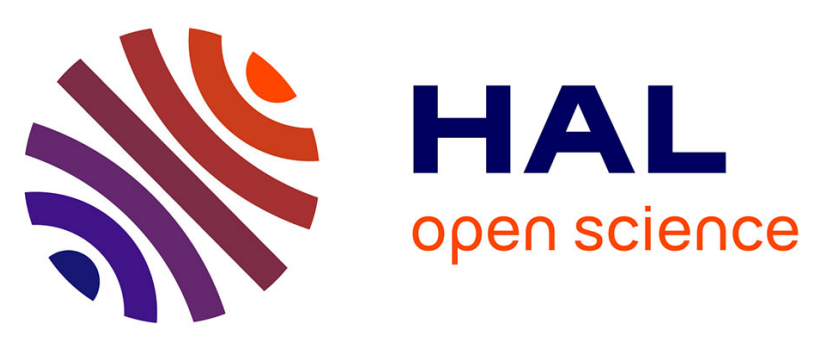

\title{
Encapsulation of Chaotropic closo -Decahydrodecaborate Clusters Within Cyclodextrins: Synthesis, Solution Studies, and DFT Calculations
}

Manal Diab, Sébastien Floquet, Mohamed Haouas, Pavel Abramov, Xavier López, David Landy, Aurélie Damond, Clement Falaise, Vincent Guérineau, David Touboul, et al.

\section{To cite this version:}

Manal Diab, Sébastien Floquet, Mohamed Haouas, Pavel Abramov, Xavier López, et al.. Encapsulation of Chaotropic closo -Decahydrodecaborate Clusters Within Cyclodextrins: Synthesis, Solution Studies, and DFT Calculations. European Journal of Inorganic Chemistry, 2019, 2019 (29), pp.33733382. 10.1002/ejic.201900602 . hal-02335711

\section{HAL Id: hal-02335711 \\ https://hal.science/hal-02335711}

Submitted on 10 Jan 2021

HAL is a multi-disciplinary open access archive for the deposit and dissemination of scientific research documents, whether they are published or not. The documents may come from teaching and research institutions in France or abroad, or from public or private research centers.
L'archive ouverte pluridisciplinaire HAL, est destinée au dépôt et à la diffusion de documents scientifiques de niveau recherche, publiés ou non, émanant des établissements d'enseignement et de recherche français ou étrangers, des laboratoires publics ou privés. 


\title{
Encapsulation of the chaotropic closo-decahydrodecaborate clusters within cyclodextrins: synthesis, solution studies and DFT calculations
}

\author{
Manal Diab, ${ }^{a, b}$ Sébastien Floquet, ${ }^{a, *}$ Mohamed Haouas, ${ }^{a}$ Pavel A. Abramov, ${ }^{c, d}$ Xavier López, ${ }^{e}$ David \\ Landy, ${ }^{\mathrm{f}}$ Aurélie Damond, ${ }^{\mathrm{a}}$ Clément Falaise, ${ }^{\mathrm{a}}$ Vincent Guérineau, ${ }^{\mathrm{g}}$ David Touboul, ${ }^{\mathrm{g}}$ Daoud Naoufal, ${ }^{\mathrm{b}, *}$ \\ Emmanuel Cadot. ${ }^{2}$
}

\begin{abstract}
This paper deals with the formation of host-guest systems between cyclodextrins and the closo-decahydrodecaborate cluster The inclusion processes, although involving weak interaction, were evidenced in solution by ESI-MS and various NMR techniques. ITC measurements provided thermodynamic parameters and DFT calculation gave some elements allowing understanding these processes.
\end{abstract}

\section{Introduction}

Boranes represent a wide family of clusters that has been historically developed by industry for rocket fuels during the past century. ${ }^{[1,2]}$ In the last decades, a number of authors demonstrated the interest of these compounds in many different domains such as energetic materials, ${ }^{[3,4]}$ ionic conductivity, ${ }^{[5]}$ ionic liquids, ${ }^{[6]}$ catalysis, ${ }^{[7,}{ }^{8]}$ material science ${ }^{[9]}$ extraction of radioactive wastes ${ }^{[10]}$ or medicine..$^{[2,11-14]}$ This last domain is by

[a] Dr M. Diab, Dr S.Floquet, Dr M. Haouas, Ms A. Damond, Dr C. Falaise, Prof. Dr. E Cadot

Institut Lavoisier de Versailles, CNRS, UVSQ, Université ParisSaclay, 45 av. des Etats-Unis, 78035 Versailles, France

E-mail: sebastien.floquet@uvsq.fr

[b] Dr M. Diab, Prof. Dr D. Naoufal

Laboratory of Organometallic and coordination chemistry, LCIO, Lebanese University, Faculty of Sciences I, Hadath, Lebanon

[c] Dr. P.A. Abramov

Nikolaiev Institute of Inorganic Chemistry SB RAS, Novosibirsk, 630090, Russia.

[d] Dr. P A Abramov

Novosibirsk State University, Novosibirsk, 630090, Russia

[e] Dr Xavier López

Universitat Rovira i Virgili, Departament de Química Física Inorgànica, Marcel·lí Domingo 1, 43007 Tarragona, Spain.

[f] Prof. Dr D. Landy

Unité de Chimie Environnementale et Interactions sur le Vivants (UCEIV, EA 4492), ULCO, Dunkerque, France.

[g] Dr V. Guérineau, Dr. D. Touboul

Institut de Chimie des Substances Naturelles, CNRS UPR2301,

Université Paris-Sud, Université Paris-Saclay, Avenue de la Terrasse, 91198 Gif-sur-Yvette Cedex, France.

Supporting Information for this article is given via a link at the end of the document† Supplementary Information available: FT-IR spectra (Figure S1); picture of the structural disorder of the boron cluster in $\mathbf{B}_{10}-\mathbf{2} \alpha \mathbf{C D}$ (Figures S2-S3); Crystallographic data (Table S1); ES-MS data (Tables S2S3); ESI-MS spectra of mixtures $B_{10} / C D$ in water (Figure S4); additional ${ }^{1} \mathrm{H}$ and ${ }^{10} \mathrm{~B}$ NMR spectra (Figures S5-S11); NMR data (Tables S4-S6) ROESY Spectra obtained with $\alpha$ and $\gamma$-CD (Figures S12-S13); details about calculations of affinity constants by DOSY NMR and data acquired by DOSY (Table S7); theoretical speciation curves for cluster/CD inclusion complexes (Figures S14-S15); Job's plot treatment with extrapolated maximum value (Figures S16-S18); ITC treatment and ITC curves obtained with $\alpha$ and $\gamma$-CD (Figure S19-S20); DFT data and figures (Table S8 and Figures S21-S22) far the most interesting field of application of such systems, especially in Boron Neutron Capture Therapy (BNCT) for cancer treatment due to the large neutron scatter cross section of ${ }^{10} \mathrm{~B}$ and the robustness and the non-toxicity of the latter in biological systems. ${ }^{[1,12-14]}$ This property thus makes the studies of the boranes derivatives of a great interest, especially the carboranes, and the derivatives of the $\left[\mathrm{B}_{12} \mathrm{H}_{12}\right]^{2-}$ and of the $\left[\mathrm{B}_{10} \mathrm{H}_{10}\right]^{2-}$ clusters. The latter offers the possibility of various selective functionalizations ${ }^{[15]}$ leading for example to closo-decaboratetriethoxysilane precursors which can be coordinated to luminescent dye doped silica nanoparticles, hence facilitating the tracing of the closo-decaborate drug pathway in BNCT. ${ }^{[16,17]}$ On their side, $\alpha-, \beta$ - and $\gamma$-Cyclodextrins (CDs) are natural macrocyclic oligosaccharides comprised of 6,7 and 8 linked Dglucopyranose units respectively. The interest in $C D$ research mainly arises from their ability to act as robust hosts to a wide variety of organic or inorganic guest species, ${ }^{[18-20]}$ as a consequence of their hydrophobic annuli being able to form host-guest complexes in aqueous solution. This property makes them very useful for drug delivery in living systems.

Driven by the biomedical applications of both borane derivatives and cyclodextrin adducts, several boranes, carboranes or metallocarboranes inclusion compounds formed with cyclodextrins by following different strategies are reported in the literature. ${ }^{[21-29]}$ In particular, Nau, Gabel, Assaf, and coworkers recently reported very interesting works focused on the inclusion compounds formed with dodecaborate derivatives. ${ }^{[30-32]}$ They notably established that the formation of very stable inclusion compounds with clusters of the type $\left[\mathrm{B}_{12} \mathrm{X}_{12}\right]^{2-}$ and $\left[\mathrm{B}_{12} \mathrm{X}_{11} \mathrm{Y}\right]^{2-}(\mathrm{X}$ $=\mathrm{H}, \mathrm{Cl}, \mathrm{Br}, \mathrm{I}$ and $\mathrm{Y}=\mathrm{OH}, \mathrm{SH}, \mathrm{NH}_{3}{ }^{+}, \mathrm{NR}_{3}{ }^{+}$) can be rationalized by a chaotropic effect. Chaotropic or super-chaotropic anions decrease the water structure in their surroundings. Their inclusion within the cavity of CDs provokes the release of water solvates with water structure recovery, which translates by a negative entropy variation and an enthalpically driven process. The super-chaotropic nature of dodecaborate derivatives has been nicely described and the closo-decahydrodecaborate cluster is expected to be chaotropic also. ${ }^{[33]}$

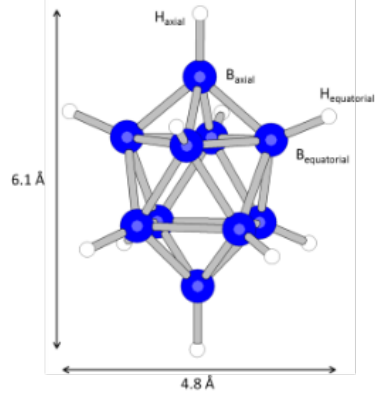

Figure 1. Molecular structure of the cluster $\left[\mathrm{B}_{10} \mathrm{H}_{10}\right]^{2-}$ highlighting the size of this cluster and the notation used for $\mathrm{B}$ and $\mathrm{H}$ atoms in the NMR part. 
In this paper, driven by the possible biological applications, we focus on the $\left[\mathrm{B}_{10} \mathrm{H}_{10}\right]^{2-}$ cluster (Figure 1). To our knowledge, the host-guest chemistry of this hydrophilic anionic cluster has not been previously reported. The aims of this study are thus i) to investigate the inclusion process of the cluster within the cavity of various cyclodextrins in aqueous solution and ii) to study the chaotropic character of this cluster in comparison with dodecaborate derivatives by ITC measurements. Finally, DFT calculations are performed in order to rationalize our results.

\section{Results and Discussion}

\section{Synthesis and structure of inclusion complexes between} $\left(\mathrm{NH}_{4}\right)_{2}\left[\mathrm{~B}_{10} \mathrm{H}_{10}\right]$ and $\mathrm{CD}$.

The synthesis of inclusion complexes between $\left(\mathrm{NH}_{4}\right)_{2}\left[\mathrm{~B}_{10} \mathrm{H}_{10}\right]$ and $\alpha-, \beta-$, and $\gamma$-cyclodextrins was investigated in distilled water by mixing both components in different ratios. In the case of $\alpha-C D$, the slow evaporation of the resulting aqueous mixture provided single colorless single crystals of a compound of formula $\left(\mathrm{NH}_{4}\right)_{2}\left[\left(\mathrm{~B}_{10} \mathrm{H}_{10}\right)(\alpha-\mathrm{CD})_{2}\right] \cdot \mathbf{2 1} \mathrm{H}_{2} \mathrm{O}$ abbreviated hereafter $B_{10-2} \alpha C D$ (see experimental section). In contrast, simila procedure applied to $\beta-$, and $\gamma$-cyclodextrins containing mixtures led systematically to the formation of colorless cluster-free crystals corresponding to the $C D$ alone. The compound $\mathbf{B}_{10}$ $2 \alpha C D$ was characterized by X-Ray diffraction, FT-IR, TGA elemental analysis, ESI-MS and NMR. Elemental analysis, in agreement with FT-IR and TGA analysis, provided a formula $\left(\mathrm{NH}_{4}\right)_{2}\left[\left(\mathrm{~B}_{10} \mathrm{H}_{10}\right)(\alpha-\mathrm{CD})_{2}\right] .21 \mathrm{H}_{2} \mathrm{O}$. (a)

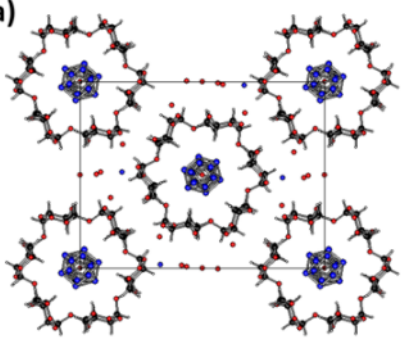

(b)

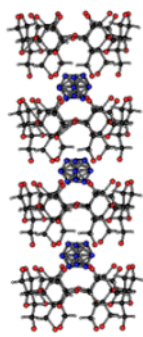

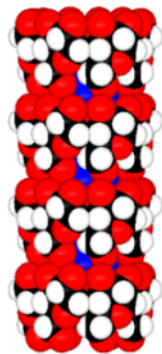

Figure 2. Ball and stick or van der Waals structural representations of the $\left(\mathrm{NH}_{4}\right)_{2}\left[\left(\mathrm{~B}_{10} \mathrm{H}_{10}\right)(\alpha-\mathrm{CD})_{2}\right] .21 \mathrm{H}_{2} \mathrm{O}$ complex. Top view (a) and side view (b) showing the organization of $C D$ in pillars and the intercalation of the boron clusters between 2 CDs.

$B_{10-2} \mathbf{C D}$ crystallizes in a chiral $P 21212$ space group based on the symmetry of $\alpha-C D$, main building units suppressing the symmetry of $\left[\mathrm{B}_{10} \mathrm{H}_{10}\right]^{2-}$ units, which produces disordering of the anion over two close positions (Figures S2-S3). Moreover the anions are not fully occupying their positions, that gives another type of disordering with water molecules of crystallization. It results on SOF found in the range $0.139-0.278$ for boron atoms. This occupancy factors are in agreement with the formula determined by elemental analysis, $\left(\mathrm{NH}_{4}\right)_{2}\left[\left(\mathrm{~B}_{10} \mathrm{H}_{10}\right)(\alpha \mathrm{CD})_{2}\right]$ $.21 \mathrm{H}_{2} \mathrm{O}$. In these conditions this disordering model is not ideal and $\mathrm{B}-\mathrm{B}$ distances are not in a perfect agreement with normal $\left[\mathrm{B}_{10} \mathrm{H}_{10}\right]^{2-}$ geometry. Therefore, the structure of $\mathrm{B}_{10}-2 \alpha C D$ can be seen as structural model showing an approximate overview of $\alpha$ $\mathrm{CD}$ and $\left[\mathrm{B}_{10} \mathrm{H}_{10}\right]^{2-}$ units positions and their loosely defined contacts

As depicted in Figure 2, the structure can be viewed as pilars of cyclodextrins interacting mutually through hydrogen bonds that interconnect alternately secondary rims and primary rims of $\alpha$ $\mathrm{CD}(\mathrm{O} \cdots \mathrm{O}=2.7-3.0 \AA)$. The organization in pillars seems to be usual for inclusion compounds as already obtained by Nau with dodecaborate derivatives ${ }^{[32]}$ or by Cadot with metallic clusters. ${ }^{[19]}$ $\left[\mathrm{B}_{10} \mathrm{H}_{10}\right]^{2-}$ clusters are intercalated between two $a-C D$ (Figure $2 b$ ) and thus interact with the primary face of one cyclodextrin and with the secondary face of the other through dihydrogen contacts between the B-H groups of the boron cluster and $\mathrm{O}-\mathrm{H}$ functions of the CDs. This assumption is in agreement with the FT-IR spectrum of $\mathbf{B}_{10-2} \alpha \mathbf{C D}$ (see Figure S1, Supporting Information, SI). Indeed, upon association with $\alpha-C D$ the B-H vibration bands of $\left[\mathrm{B}_{10} \mathrm{H}_{10}\right]^{2-}$ become sharper with a shift of about $8 \mathrm{~cm}^{-1}$ toward lower values, typical of the formation of dihydrogen contacts between $\mathrm{B}-\mathrm{H}$ groups of the $\left[\mathrm{B}_{10} \mathrm{H}_{10}\right]^{2-}$ cluster and or $\mathrm{O}-\mathrm{H}$ functions of the cyclodextrin. ${ }^{[34]}$ Finally, the two counter cations $\mathrm{NH}_{4}{ }^{+}$and the 21 water molecules have been found disordered and appear mainly located in the vicinity of the hydroxyl group of the $\alpha-C D$ (see Figure 2a)

\section{Studies in solution.}

\section{Characterization of $B_{10-2} \alpha C D$ by Mass Spectrometry}

The single crystals of compound $\mathbf{B}_{10-2} \alpha \mathbf{C D}$ were characterized by mass spectrometry by using either MALDI-TOF or ESI-MS techniques. As shown in Figure $3 a$ and in Table S2 (SI), the MALDI-TOF spectrum of $B_{10}-2 \alpha C D$ reveals the presence of peaks assigned to $1: 1$ adducts between $\alpha-C D$ and $\left[\mathrm{B}_{10} \mathrm{H}_{10}\right]^{2-}$ clusters and some peaks attributed to $\alpha-C D$ alone associated to molecules of the matrix or solvates. No peak assigned to $1: 2$ adduct was observed and two minor peaks at $\mathrm{m} / \mathrm{z} 1943.7$ and 1996.6 are assigned to dimers of $\alpha-C D$, which evidence the propensity of cyclodextrins to give aggregates, accordingly to NMR studies of Valente et al. ${ }^{[35,36]}$ On its side, ESI-Mass spectrum recorded on a $10^{-5} \mathrm{M}$ aqueous solution of $B_{10-2} \alpha C D$ (Figure 3b), displays two major peaks at $\mathrm{m} / \mathrm{z} 545.5$ and $\mathrm{m} / \mathrm{z}$ 1031.9 which are respectively assigned to the $1: 1$ and $1: 2$ adducts, $\left[\left(\mathrm{B}_{10} \mathrm{H}_{10}\right)(\alpha \mathrm{CD})\right]^{2-}$ and $\left[\left(\mathrm{B}_{10} \mathrm{H}_{10}\right)(\alpha \mathrm{CD})_{2}\right]^{2-}$ species, while a minor peak at 1092.0 is attributed to the protonated species $\left[\mathrm{H}\left(\mathrm{B}_{10} \mathrm{H}_{10}\right)(\alpha \mathrm{CD})\right]^{-}$( $\mathrm{m} / \mathrm{z}$ calculated 1092.0). In summary, both techniques evidences the formation of complexes between $\alpha-C D$ and $\left[\mathrm{B}_{10} \mathrm{H}_{10}\right]^{2-}$ with stoechiometries of $1: 1$ and $1: 2$ in agreement with structural data.

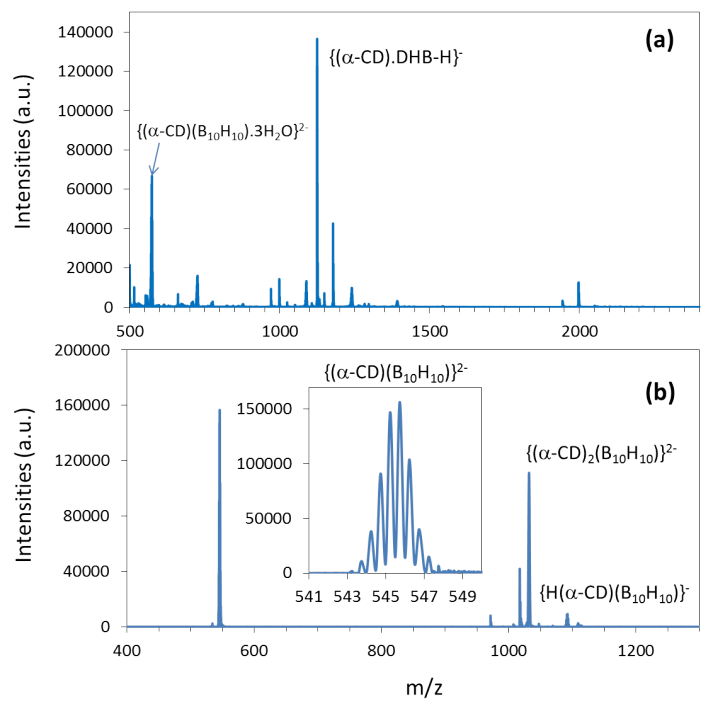

Figure 3. MALDI-TOF spectrum (a) and ESI-MS spectrum in water (b) of $B_{10-2} \alpha C D$. 


\section{ESI-MS studies of $B_{10} / C D$ mixtures in aqueous solution}

In addition to the characterization of $B_{10-2} \alpha C D$, ESI-MS studies were extended to $10^{-4} \mathrm{M}$ aqueous solution of synthetic mixtures between $\left(\mathrm{NH}_{4}\right)_{2}\left[\mathrm{~B}_{10} \mathrm{H}_{10}\right]$ and $\alpha-, \beta-$, or $\gamma-\mathrm{CD}$ with ratios $\mathrm{B}_{10} / \mathrm{CD}=$ $1: 1$ and $1: 2$. Resulting ESI-MS spectra are given in Figure S4 (SI), while Table S3 (SI) gathers the obtained data. As a common feature, all spectra exhibit some peaks assigned to $\left[\mathrm{B}_{10} \mathrm{H}_{10}\right]^{2-}$ alone as mono-anionic species $\left\{\mathrm{H}\left[\mathrm{B}_{10} \mathrm{H}_{10}\right]\right\}^{-}$and $\mathrm{CD}$ alone as monoanionic species $\{[C D]-H\}^{-}$and $\left\{\mathrm{CD}\left(\mathrm{H}_{2} \mathrm{O}\right)_{7}-\mathrm{H}\right\}$. In case of $\alpha-C D$ (Figures S4a-b), the peaks at $\mathrm{m} / \mathrm{z} 545.7$ and 1113.4 are unambiguously attributed to the $1: 1$ adducts $\left\{\left(\mathrm{B}_{10} \mathrm{H}_{10}\right)(\alpha-\mathrm{CD})\right\}^{2-}$ and $\left\{\mathrm{Na}\left(\mathrm{B}_{10} \mathrm{H}_{10}\right)(\alpha-\mathrm{CD})\right\}$, while a $1: 2$ adduct $\left\{\left(\mathrm{B}_{10} \mathrm{H}_{10}\right)(\alpha-C D)_{2}\right\}^{2-}$ is observed at $\mathrm{m} / \mathrm{z} 1031.8$. Even if the $1: 1$ adduct is the major component, the proportion of the 1:2 adduct is far from negligible and tends logically to increase when the $\mathrm{CD} / \mathrm{B}_{10}$ ratio in the synthetic mixture increases. The cases of $\beta$ $C D$ and $\gamma-C D$ are relatively similar. In both cases, the formation of $1: 1$ adducts as $\left\{\left(\mathrm{B}_{10} \mathrm{H}_{10}\right)(\mathrm{CD})\right\}^{2-}$ and $\left\{\mathrm{Na}\left(\mathrm{B}_{10} \mathrm{H}_{10}\right)(\mathrm{CD})\right\}^{-}$species predominates even in presence of an excess of $C D$, in agreement with the fact that the size of the boron cluster probably matches better the size of the cavities of $\beta-C D$ and $\gamma-$ $C D$. The formation of $1: 2$ adducts of general formula $\left\{\left(\mathrm{B}_{10} \mathrm{H}_{10}\right)(\mathrm{CD})_{2}\right\}^{2-}$ is observed in both cases as minor species, and probably results from the formation of aggregates.

\section{NMR study of the interaction between cyclodextrins and $\left(\mathrm{NH}_{4}\right)_{2}\left[\mathrm{~B}_{10} \mathrm{H}_{10}\right]$ in $\mathrm{D}_{2} \mathrm{O}$.}

Encapsulation of guest molecules within the cavity of cyclodextrin is easily followed by ${ }^{1} \mathrm{H}$ NMR titrations. ${ }^{[19,26,32,37,38]}$ ${ }^{1} \mathrm{H}\left\{{ }^{11} \mathrm{~B}\right\}$ and ${ }^{11} \mathrm{~B}\left\{{ }^{1} \mathrm{H}\right\}$ NMR titrations of cyclodextrins by $\left(\mathrm{NH}_{4}\right)_{2}\left[\mathrm{~B}_{10} \mathrm{H}_{10}\right]$ were monitored by maintaining a total concentration of $\mathrm{CD}+\left[\mathrm{B}_{10} \mathrm{H}_{10}\right]^{2-}$ constant at $0.1 \mathrm{M}$ for $\alpha$-and $\gamma-C D$ or $0.033 M$ for $\beta-C D$. The ${ }^{1} H\left\{{ }^{11} B\right\}$ and ${ }^{11} B\left\{{ }^{1} H\right\}$ NMR spectra of various $\beta-C D /\left[\mathrm{B}_{10} \mathrm{H}_{10}\right]^{2-}$ mixtures are given in Figure 4 and S9 (SI), while those corresponding to the $\alpha$ $\mathrm{CD} /\left[\mathrm{B}_{10} \mathrm{H}_{10}\right]^{2-}$ and $\gamma-\mathrm{CD} /\left[\mathrm{B}_{10} \mathrm{H}_{10}\right]^{2-}$ systems are depicted in Figures S7-S8 and S10-S11 (SI), respectively. Chemical shifts are gathered in Tables S4-S6 in supporting information.

$\alpha-C D$ displays a peak at 5.00 ppm for $\mathrm{H} 1$ and the other $\mathrm{H}$ peaks are observed in the range between 3.44 and $4.01 \mathrm{ppm}$. As shown in Figure $\mathrm{S} 7$, the increasing of $\left[\mathrm{B}_{10} \mathrm{H}_{10}\right]^{2-} / \mathrm{CD}$ ratio provokes a slight shift of protons $\mathrm{H} 3$ (internal protons accessible through the secondary face) and protons $\mathrm{H} 5$ (internal protons accessible through the primary face) of $\alpha$-cyclodextrin in agreement with the structure of $\mathbf{B}_{10-2} \alpha \mathbf{C D}$ for which interaction of $\mathrm{B}-\mathrm{H}$ groups with these two protons can be supposed. The shift remains very small since a maximum variation of +0.05 and +0.03 ppm is observed for $\mathrm{H} 3$ and $\mathrm{H} 5$, respectively, while no significant shift was observed for the other protons of the $\alpha-C D$. Concomitantly, $\mathrm{H}_{\mathrm{e}}$ and $\mathrm{H}_{\mathrm{a}}$ signals of boron cluster remain also almost unaffected with a maximum shift of around $-0.02 \mathrm{ppm}$ for $\mathrm{H}_{\mathrm{a}}$ and no shift for $\mathrm{H}_{\mathrm{e}}$. On the Boron NMR side (see Figure S8), no shift was observed for $\mathrm{B}_{\mathrm{a}}$ (see Table S2, SI) while a maximum shift of -0.05 ppm appears for $B_{e}$ in comparison with free boron cluster (Figure S6, SI).

Because of the low solubility of $\beta-C D, N M R$ titration with $\beta-C D$ was carried out with a total concentration of $33 \mathrm{mM}$. As shown in Figure 6 , upon increasing the proportion of the boron cluster, the $\mathrm{H} 3$ and $\mathrm{H} 5$ internal protons of $\beta-C D$ are significantly shifted up to +0.06 and +0.19 ppm respectively (see Table S5, SI), while the other protons are much less affected. Concomitantly, both the apical and equatorial protons of $\left[\mathrm{B}_{10} \mathrm{H}_{10}\right]^{2-}$ are shifted up to 0.09 and $-0.08 \mathrm{ppm}$ respectively, in agreement with the encapsulation process of the cluster within the cavity of the $\beta-C D .{ }^{[38]}$ Accordingly, the ${ }^{11} \mathrm{~B}\left\{{ }^{1} \mathrm{H}\right\}$ NMR spectra (Figure S9, SI) shows a shift of the signals of the apical and axial boron atoms, $B_{a}$ and $B_{e}$. The former exhibits a shift towards more negative chemical shift up to $-0.14 \mathrm{ppm}$, while a positive shift of +0.05 $\mathrm{ppm}$ is recorded for $B_{\mathrm{e}}$. These chemical shift variations are higher than those observed with $\alpha-C D$, which suggest stronger interaction and thus a more efficient encapsulation of $\left[\mathrm{B}_{10} \mathrm{H}_{10}\right]^{2-}$ within the cavity of $\beta-C D$.

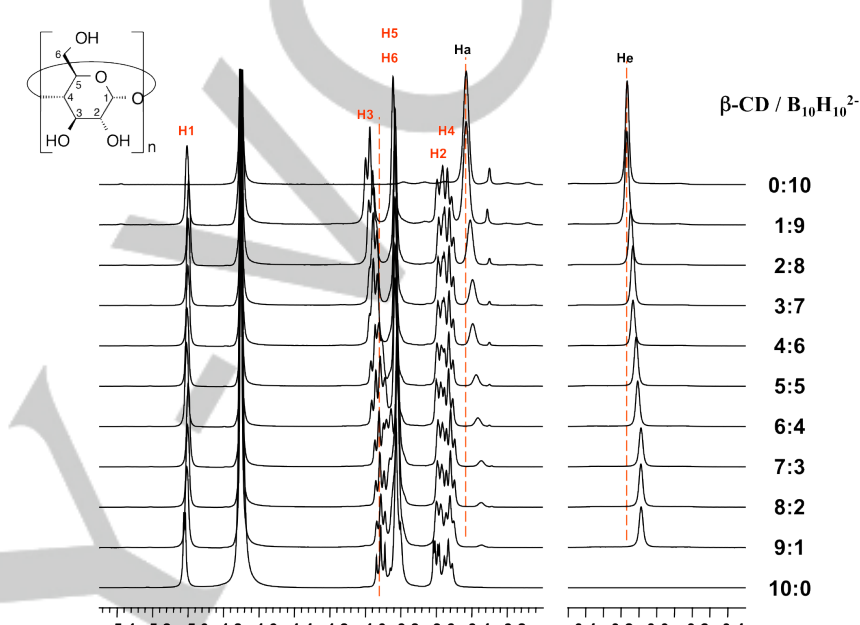

Figure 4: ${ }^{1} \mathrm{H}\left\{{ }^{11} \mathrm{~B}\right\}$ NMR spectra in $\mathrm{D}_{2} \mathrm{O}$ for different ratios $\beta-\mathrm{CD} / \mathrm{B}_{10}$ (tota concentration $=0.033 \mathrm{M}$ )

Finally, the titration with $\gamma-C D$ was performed with a total concentration of $0.1 \mathrm{M}$ in $\mathrm{D}_{2} \mathrm{O}$. The ${ }^{1} \mathrm{H}\left\{{ }^{11} \mathrm{~B}\right\}$ and ${ }^{11} \mathrm{~B}\left\{{ }^{1} \mathrm{H}\right\}$ NMR spectra are given in Figures $\mathrm{S} 10$ and $\mathrm{S} 11$ in SI. As seen in Figure S10 and in Table S6 (SI), increasing the quantity of the boron cluster provokes a shift of the signals of $\mathrm{H} 3, \mathrm{H} 5$ and $\mathrm{H} 6$ protons of $\gamma-C D$ with a maximum chemical shift variations of $+0.08,+0.19$ and +0.04 ppm, respectively. Concerning the boron cluster, $\mathrm{H}_{a}$ and $\mathrm{H}_{e}$ protons are shifted up to -0.13 and -0.11 ppm when the molar faction of $C D$ increases, while $B_{a}$ undergoes a shift of $-0.14 \mathrm{ppm}$ and $\mathrm{B}_{\mathrm{e}}$ remains unaffected. As observed for $\beta-C D$, this behavior is in agreement with the inclusion of the $\left[\mathrm{B}_{10} \mathrm{H}_{10}\right]^{2-}$ cluster within the cavity of $\gamma-C D$.

The interaction between the $C D s$ and $\left[\mathrm{B}_{10} \mathrm{H}_{10}\right]^{2-}$ in $\mathrm{D}_{2} \mathrm{O}$ is confirmed by ${ }^{1} \mathrm{H}$ ROESY NMR as well. For a $1: 1$ mixture of $\alpha$ $\mathrm{CD} /\left[\mathrm{B}_{10} \mathrm{H}_{10}\right]^{2-}$, the interactions between equatorial protons of the boron cluster $\mathrm{H}_{\mathrm{e}}$, with $\mathrm{H}_{3}$ and $\mathrm{H}_{5}$ internal protons of the $\alpha-C D$ are revealed through the occurrence of cross REO peaks (see Figure S12, SI). The encapsulation processes of the $\left[\mathrm{B}_{10} \mathrm{H}_{10}\right]^{2-}$ cluster within the cavities of $\beta-C D$ and $\gamma-C D$ are also evidenced by the ${ }^{1} \mathrm{H}-{ }^{1} \mathrm{H}\left\{{ }^{11} \mathrm{~B}\right\}$ ROESY NMR spectra shown in Figure 5 and in Figure S13, respectively. For $\beta-C D$, the cross REO peaks between the unresolved resonances of $\mathrm{H}_{5} / \mathrm{H}_{6}$ of the $\mathrm{CD}$ and both $\mathrm{H}_{\mathrm{a}}$ and $\mathrm{H}_{\mathrm{e}}$ of $\left[\mathrm{B}_{10} \mathrm{H}_{10}\right]^{2-}$ clearly indicate the interaction between hydrogen atoms of the boron cluster and the CDs, while cross REO peaks between the signals of $\mathrm{H}_{3} / \mathrm{H}_{5}$ (superimposed resonances) of the $C D$ and $\mathrm{H}_{e}$ and between signals of $\mathrm{H}_{6}$ proton of the CD and $\mathrm{H}_{\mathrm{a}}$ of boron cluster are observed in the case of $\gamma$ CD.

Finally, Job's plots focused on the chemical shift variations of the $\mathrm{H} 3$ internal protons for $\alpha-C D$, or $\mathrm{H} 5$ protons for $\beta-C D$ and $\gamma-$ 
CD allows determining the stoichiometry of the adducts in solution. By plotting the product of the molar fraction in cyclodextrin $\mathrm{X}_{\mathrm{CD}}$ in the mixture by the difference between observed chemical shift of $\mathrm{H} 3$ or $\mathrm{H} 5$ in presence and absence of $\left[\mathrm{B}_{10} \mathrm{H}_{10}\right]^{2-}\left(\delta_{\mathrm{obs}}-\delta_{\mathrm{H} 3}\right.$ or $\left.\mathrm{H} 5 \mathrm{CD}\right)$ as a function of the molar fraction in cyclodextrin $X_{C D}$, the Job's plot drawn in Figures S15-S17 (SI) give unambiguously curves passing by a maximum at $\mathrm{X}_{\mathrm{CD}}=0.5$, which demonstrates the formation of $1: 1$ adducts between $\left[\mathrm{B}_{10} \mathrm{H}_{10}\right]^{2-}$ and the three $\mathrm{CDs}$ in solution.

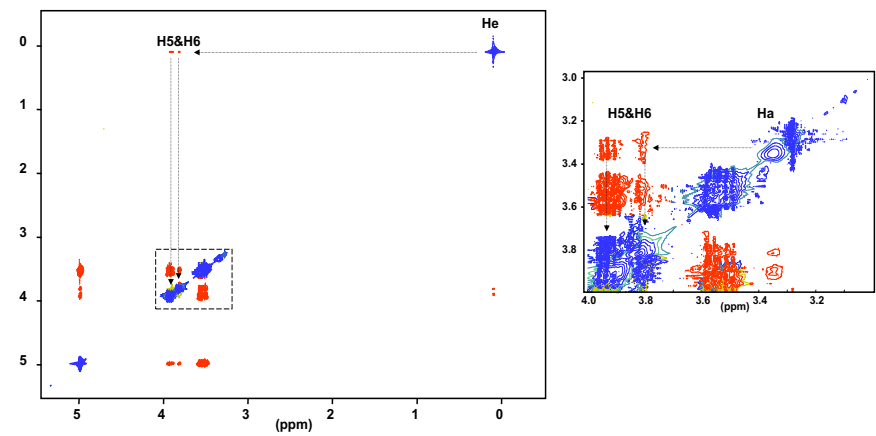

Figure 5: ${ }^{1} \mathrm{H}-{ }^{1} \mathrm{H}\left\{{ }^{11} \mathrm{~B}\right\}$ ROESY NMR spectrum in $\mathrm{D}_{2} \mathrm{O}$ of a mixture with ratio $\beta$ $\mathrm{CD} /\left[\mathrm{B}_{10} \mathrm{H}_{10}\right]^{2-} 1: 1$

\section{Association constants and thermodynamic data by ITC.}

The association constant can be determined either from NMR chemical shifts by using nonlinear least-squares method applied to Job's plots or by ${ }^{1} \mathrm{H}$ DOSY NMR, which has also proved to be efficient for the determination of association constants of labile host-guest complexes in aqueous solution (see the Supporting Information for more details). ${ }^{[39]}$

Table 1. Formation constant $\mathrm{K}\left(\mathrm{M}^{-1}\right)$ of the $1: 1$ inclusion complexes formed between $\left(\mathrm{NH}_{4}\right)_{2}\left[\mathrm{~B}_{10} \mathrm{H}_{10}\right]$ and native cyclodextrins ( $\alpha-\mathrm{CD}, \beta-\mathrm{CD}$ and $\left.\gamma-\mathrm{CD}\right)$ obtained from ITC ${ }^{1} \mathrm{H}$ chemical shifts and DOSY NMR data, at $298 \mathrm{~K}$

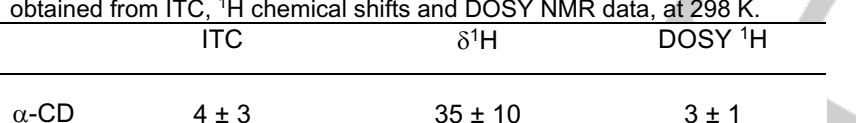

$\beta-C D$

$40 \pm 4$

$110 \pm 70$

$88 \pm 30$

$\gamma-C D$

$19 \pm 5$

$60 \pm 20$

$73+30$

As shown in Table 1, the obtained values by the two NMR methods are of the same order of magnitude and follow the same trend evidencing a very low association constant with $\alpha$ $C D$, while the optimal constant is found with $\beta-C D$. However, the accuracies of calculations are too low, and probably originate from the approximations done in the two NMR methods.

More reliable data could be obtained from isotherma calorimetric titration (ITC) measurements. As NMR experiments showed that the studied systems were characterized by weak interactions between the host and the guest, it became obvious that dedicated protocols should be employed, in order to replace the classical titration experiment, which is not suitable for weak affinities. In particular, it has been demonstrated that release annihilated release and reverse titration experiments could significantly increase the accuracy of ITC characterization in the case of weak complexes. ${ }^{[40]}$ As a result, these three protocols were applied for both $\beta-C D$ and $\gamma$-CD inclusion compounds. The corresponding ITC thermograms and isotherms are presented in
Figure 6 and in Figure S19 (SI), respectively, while experimental details are given in experimental section and in Supporting Information.

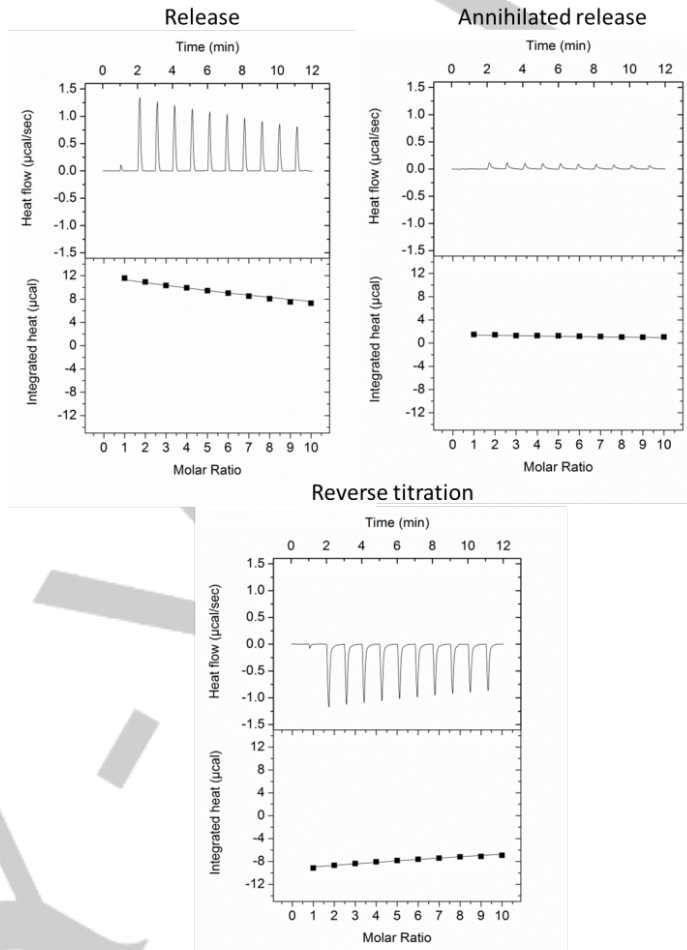

Figure 6: ITC thermograms (upper part) and isotherms (lower part) for the system $\beta-\mathrm{CD} /\left(\mathrm{NH}_{4}\right)_{2}\left[\mathrm{~B}_{10} \mathrm{H}_{10}\right]$. Dots and lines correspond to experimental and theoretical heats, respectively.

According to complementary information contained in all isotherms, and despite their flat character, the global analysis of the three kinds of experiment lead, for each system, to an accurate characterization of association constants, which compare well with NMR results (Table 1), in terms of order of magnitude and of relative affinity from one cyclodetrin to another. Thermodynamic parameters are summarized in Table 2.

All experimental data were in agreement with a 1:1 stoichiometric model. In addition, as expected from a qualitative evaluation of the ITC isotherms, inclusion of $\left(\mathrm{NH}_{4}\right)_{2}\left[\mathrm{~B}_{10} \mathrm{H}_{10}\right]$ in $\beta$ $\mathrm{CD}$ and $\gamma-\mathrm{CD}$ were characterized by an important compensation between a strong enthalpic stabilization and a slightly lower entropic destabilization, leading to weak but significant affinities: 40 and $19 \mathrm{M}^{-1}$ for $\beta-C D$ and $\gamma-C D$, respectively. In the case of $\alpha$ $C D$, a nearly athermic behavior was observed for the release experiment (Figure S20, SI). Such a result was indicative of very weak affinity and/or inclusion enthalpy, in agreement with NMR studies. In order to overcome this calorimetric silence of the $\alpha$ $\mathrm{CD} /\left(\mathrm{NH}_{4}\right)_{2}\left[\mathrm{~B}_{10} \mathrm{H}_{10}\right]$ system, a competitive release with $\beta-\mathrm{CD}$ was also implemented, allowing a quantitative evaluation of the $\alpha$ $\mathrm{CD}-\left(\mathrm{NH}_{4}\right)_{2}\left[\mathrm{~B}_{10} \mathrm{H}_{10}\right]$ complex by increasing the recorded signals. Indeed, when the syringe solution used in the release experiment was injected in the cell filled with a $5 \mathrm{mM} \beta-C D$ solution instead of pure water, significant negative signals were measured. These heats were induced not only by the inclusion of free $\left(\mathrm{NH}_{4}\right)_{2}\left[\mathrm{~B}_{10} \mathrm{H}_{10}\right]$ inside $\beta-\mathrm{CD}$, but also by the transfer in $\beta$ $\mathrm{CD}$ cavity of the $\left(\mathrm{NH}_{4}\right)_{2} \mathrm{~B}_{10} \mathrm{H}_{10}$ molecules which were initially included in $\alpha-C D$. As the $\beta-C D-\left(\mathrm{NH}_{4}\right)_{2}\left[\mathrm{~B}_{10} \mathrm{H}_{10}\right]$ complex was already characterized, this competitive release experiment enabled the evaluation of the strength of the $\alpha-C D$ - 
$\left(\mathrm{NH}_{4}\right)_{2}\left[\mathrm{~B}_{10} \mathrm{H}_{10}\right]$ inclusion compound. Despite the large relative uncertainty on the formation constant, the obtained results showed undoubtedly the weaker affinity of $\left(\mathrm{NH}_{4}\right)_{2}\left[\mathrm{~B}_{10} \mathrm{H}_{10}\right]$ for $\alpha$ $C D$ if compared to $\beta-C D$ and $\gamma-C D$.

Table 2. Enthalpy, entropy and free energy of $1: 1$ inclusion complexes formation between $\left(\mathrm{NH}_{4}\right)_{2}\left[\mathrm{~B}_{10} \mathrm{H}_{10}\right]$ and native cyclodextrins $(\alpha-\mathrm{CD}, \beta-\mathrm{CD}$ and $\gamma-$ CD), obtained from ITC data, at $298 \mathrm{~K}$

\begin{tabular}{lccc}
\hline & $\Delta \mathrm{H}\left(\mathrm{kcal} . \mathrm{mol}^{-1}\right)$ & $\mathrm{T} \Delta \mathrm{S}\left(\mathrm{kcal}^{\mathrm{mol}}{ }^{-1}\right)$ & $\Delta \mathrm{G}\left(\mathrm{kcal}^{\mathrm{mol}}{ }^{-1}\right)$ \\
\hline$\alpha-\mathrm{CD}$ & $-6 \pm 4$ & $-5 \pm 4$ & $-0.7 \pm 0.4$ \\
$\beta-\mathrm{CD}$ & $-8.3 \pm 0.2$ & $-6.1 \pm 0.3$ & $-2.2 \pm 0.1$ \\
$\gamma-\mathrm{CD}$ & $-9.5 \pm 0.5$ & $-7.7 \pm 0.7$ & $-1.8 \pm 0.2$
\end{tabular}

Finally, from a thermodynamic point of view, the negative enthalpy values found in all cases demonstrate the process of encapsulation of the $\mathrm{B}_{10}$ cluster is enthalpically driven while the negative entropy variations indicate that the binding of the dianionic $\left[\mathrm{B}_{10} \mathrm{H}_{10}\right]^{2-}$ cluster to the unpolar cyclodextrin pockets is associated to a chaotropic effect, an effect which has been evidenced by $\mathrm{Nau}$ and coworkers for dodecaboranes derivatives $\left[\mathrm{B}_{12} \mathrm{X}_{12}\right]^{2-[32]}$ This effect can be explained by the migration of strongly chaotropic borate anions from the aqueous medium into the pockets of $C D$ allowing the recovery of the water structure distorted by the chaotropes. As mentioned in a recent review, $\left[\mathrm{B}_{10} \mathrm{H}_{10}\right]^{2-}$ cluster is expected to be a chaotropic anion. ${ }^{[33]}$ It has also been demonstrated on a series of polyoxometalates that the strength of the chaotropic behavior is notably related to the volume charge density of the anion, meaning that lower chaotropic effect is expected when the volume charge density increases. ${ }^{[41]}$ From $\left[\mathrm{B}_{12} \mathrm{H}_{12}\right]^{2-}$ to $\left[\mathrm{B}_{10} \mathrm{H}_{10}\right]^{2-}$, the volume charge density increases significantly and therefore the chaotropic character of the latter is reduced, which translates by a decreases of the entropy variation associated to the recovery of the water structure upon inclusion within the CDs. Additionally, as commonly observed for cyclodextrins, the increasing of enthalpic contribution is counterbalanced by an increasing entropy penalty which is called enthalpy-entropy compensation. Figure 7 gives the $\Delta \mathrm{H}$ vs $\mathrm{T} \Delta \mathrm{S}$ plot associated to the $1: 1$ complexes of $\left[\mathrm{B}_{10} \mathrm{H}_{10}\right]^{2-}$ with $\mathrm{CDs}$ (red dots) in comparison to thermodynamic data reported by Nau for $1: 1$ complexes formed between $\left[\mathrm{B}_{12} \mathrm{X}_{12}\right]^{2-}$ derivatives and $\gamma-\mathrm{CD}^{[32]}$ (blue dots) and $1: 1$ complexes formed between $\left[\operatorname{Re}_{6} Q_{8}(C N)_{6}\right]^{2-}$ clusters $(Q=S$, Se, $\mathrm{Te})$ and $\gamma$-CD (green dots). ${ }^{[18]}$ The thermodynamic parameters determined for the adducts obtained with $\left[\mathrm{B}_{10} \mathrm{H}_{10}\right]^{2-}$ are in agreement with this correlation and low entropy variations are consequently associated to low enthalpy variations and low association constants for inclusion complexes formed with $\left[\mathrm{B}_{10} \mathrm{H}_{10}\right]^{2-}$.

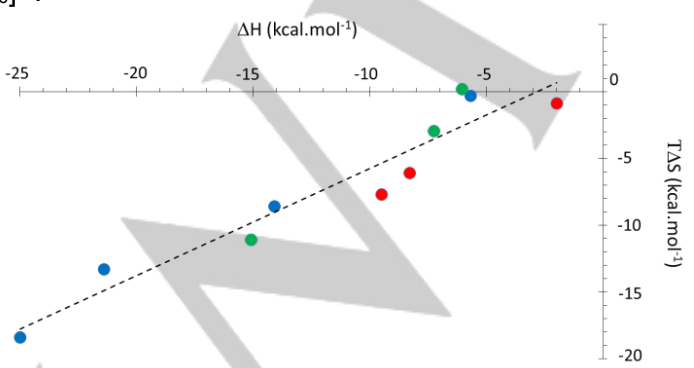

Figure 7: Enthalpy-entropy compensation plot for 1:1 complexes formed between $\gamma$-CDs and $\left[B_{12} X_{12}\right]^{2-}$ derivatives (blue dots from ref 32 ), and clusters $\left[\operatorname{Re}_{6} \mathrm{Q}_{8}(\mathrm{CN})_{6}\right]^{2-}(\mathrm{Q}=\mathrm{S}$, Se, Te ; green dots from ref 18$)$ and $\left[\mathrm{B}_{10} \mathrm{H}_{10}\right]^{2-}($ red dots)

\section{DFT Calculations}

A theoretical study has been carried out for $\left[\mathrm{B}_{10} \mathrm{H}_{10}\right]^{2-}$ and $\left[\mathrm{B}_{12} \mathrm{H}_{12}\right]^{2-}$ for comparison, the three cyclodextrins $\alpha-C D, \beta-C D$ and $\gamma-C D$ and the 1:1 inclusion complexes derived. The main results are gathered in Table S8 (SI) and Table 3.

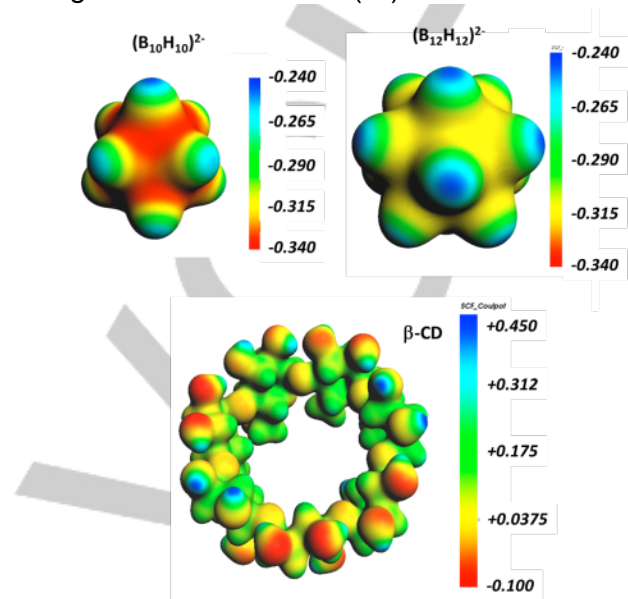

Figure 8: Molecular electrostatic potential of $\beta-C D,\left[\mathrm{~B}_{10} \mathrm{H}_{10}\right]^{2-}$ and $\left[\mathrm{B}_{12} \mathrm{H}_{12}\right]^{2-}$ depicted on an isodensity surface with value $\rho=0.005$ a.u. Red and blue colours represent the most and least nucleophilic regions of the molecule, respectively. The $\beta-C D$ cavity surface is characterized by slightly positive potentials, whereas the anions show all-negative electrostatic potentials.

As shown in Figure 8 , the anionic $\left[\mathrm{B}_{10} \mathrm{H}_{10}\right]^{2-}$ and $\left[\mathrm{B}_{12} \mathrm{H}_{12}\right]^{2-}$ clusters feature some negative charge density located in the $\mathrm{H}$ atoms, according to their hydride character (see also Figure S21 in $\mathrm{SI}$ ), which can generate dihydrogen bonds with $\mathrm{O}-\mathrm{H}$ functions. ${ }^{[34]}$ Furthermore the surface negative charge density of boranes and the slightly positively charged CD pockets can logically favour the formation of inclusion complexes.

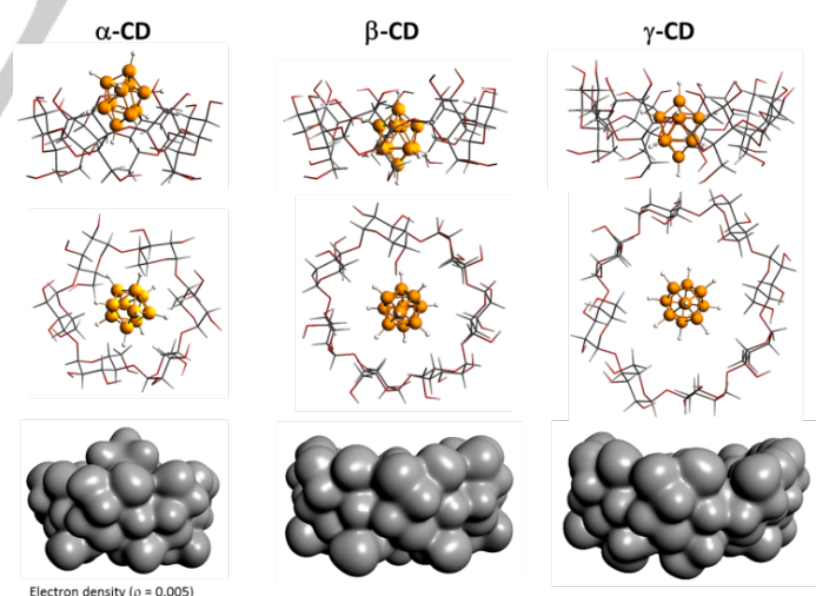

Figure 9: Computed models obtained for 1:1 inclusion complexes between $\left[\mathrm{B}_{10} \mathrm{H}_{10}\right]^{2-}$ and cyclodextrins. The bottom pictures represent an arbitrary electron isodensity surface ( $\rho=0.005$ a.u.) of the optimized models

Figure 9 shows structural models of 1:1 inclusion complexes involving $\left[\mathrm{B}_{10} \mathrm{H}_{10}\right]^{2-}$ and $\mathrm{CDs}$. The $\alpha-C D$ cavity is too small to totally encapsulate the boron cluster, which mostly interacts with the upper rim. This feature, at first sight inconsistent with crystallographic X-ray measurements, is due to the DFT calculation describing the complex in solution with $\left[\mathrm{B}_{10} \mathrm{H}_{10}\right]^{2-}$ placed close to the secondary face of the $\alpha-C D$, more stabilizing 
and larger in diameter than the primary one. In contrast, the $\mathrm{X}$ ray data show intercalation and interaction of $\left[\mathrm{B}_{10} \mathrm{H}_{10}\right]^{2-}$ units between two $\alpha-C D$ simultaneously in the crystalline phase, forming 1D "pillars", with each $\left[\mathrm{B}_{10} \mathrm{H}_{10}\right]^{2-}$ surrounded by one primary and one secondary face and each $\left[\mathrm{B}_{10} \mathrm{H}_{10}\right]^{2-}$ stabilized ca. $50 \%$ from each $\alpha-C D$. In consequence, the inorganic unit has a weaker interaction with each $\alpha-C D$ unit, at more external position, than in the DFT situation, where $\left[\mathrm{B}_{10} \mathrm{H}_{10}\right]^{2-}$ is lying on top of the $\alpha-C D$. Thus, the DFT structure described for a $\left[\mathrm{B}_{10} \mathrm{H}_{10}\right]^{2-} / \alpha-\mathrm{CD}$ pair is interesting for the association property in solution since it describes more approximately this phase than the X-ray data do.

Table 3. DFT energies (in eV) for the 1:1 inclusion complexes formed between cyclodextrins and boron clusters in aqueous solution

\begin{tabular}{lcccccc}
\hline Structure & $E^{\mathrm{a}}$ & $\mathrm{NEI}^{\mathrm{b}}$ & $\mathrm{GD}^{\mathrm{c}}$ & $\begin{array}{c}\text { Interaction } \\
\text { Energy }\end{array}$ & $\mathrm{SE}$ & $\mathrm{SEI}^{\mathrm{d}}$ \\
\hline$\alpha-\mathrm{CD} \mathrm{B}_{10} \mathrm{H}_{10}$ & -869.055 & 0.467 & & 0.0682 & -8.83 & 2.33 \\
Frag. $\alpha-\mathrm{CD}$ & -757.012 & & 0.362 & & -3.06 & \\
Frag. $\mathrm{B}_{10} \mathrm{H}_{10}$ & -112.111 & & 0.0368 & & -8.03 & \\
\hline$\beta-\mathrm{CD} \mathrm{B}_{10} \mathrm{H}_{10}$ & -995.806 & -0.0495 & & -0.248 & -8.37 & 3.42 \\
Frag. $\beta-\mathrm{CD}$ & -883.440 & & 0.169 & & -3.93 & \\
Frag. $\mathrm{B}_{10} \mathrm{H}_{10}$ & -112.118 & & 0.0298 & & -8.03 & \\
\hline$\gamma-\mathrm{CD} \mathrm{B}_{10} \mathrm{H}_{10}$ & -1121.23 & 0.530 & & -0.0245 & -9.86 & 2.21 \\
Frag. $\gamma-\mathrm{CD}$ & -1009.09 & & 0.520 & & -4.26 & \\
Frag. $\mathrm{B}_{10} \mathrm{H}_{10}$ & -112.114 & & 0.0338 & & -8.00 & \\
\hline
\end{tabular}

${ }^{a}$ In the geometry of the complex. This value includes solvation energy (SE) if calculation with COSMO. ${ }^{b} \mathrm{NEI}$ : Net Energy Increase, ( $\left.\mathrm{E}_{\text {prod }}-\mathrm{E}_{\text {react }}\right) .{ }^{\mathrm{c}} \mathrm{GD}$ : Geometry distortion ( $E_{\text {frag complex }}-E_{\text {frag free }}$ ). ${ }^{d}$ SEI: Solvation Energy increment $\left(S E_{\text {prod }}-S E_{\text {react }}\right)$. If positive, poorer solvation in products than in reactants.

Conversely, the $\left[\mathrm{B}_{10} \mathrm{H}_{10}\right]^{2-}$ can be inserted into $\beta-C D$ and $\gamma-C D$, in agreement with NMR data showing a stronger effect on the chemical shift of the internal protons $\mathrm{H} 3$ and $\mathrm{H} 5$ upon encapsulation of $\left[\mathrm{B}_{10} \mathrm{H}_{10}\right]^{2-}$. The $\beta-\mathrm{CD}$ cavity and $\left[\mathrm{B}_{10} \mathrm{H}_{10}\right]^{2-}$ match in size, while $\gamma-C D$ has an over-dimensioned cavity. These results should be related to the affinity constant determined by NMR and by ITC evidencing a low constant value for $\alpha-C D$ and a large affinity constant with $\beta-C D$. It should be also compared with literature data that show an optimal affinity constant of $\left[\mathrm{B}_{12} \mathrm{H}_{12}\right]^{2-}$ for the larger $\gamma$-CD cavity, in consonance with the larger size of this cluster compared to $\left[\mathrm{B}_{10} \mathrm{H}_{10}\right]^{2-}$. [32]

\section{Calculations with solvation effects}

DFT results suggest that encapsulation of $\left[\mathrm{B}_{10} \mathrm{H}_{10}\right]^{2-}$ is much less favoured in $\alpha$ - and $\gamma$-CD (net energy increase, NEI $=0.467$ and $0.530 \mathrm{eV}$, respectively) than in $\beta-\mathrm{CD}(\mathrm{NEI}=-0.050 \mathrm{eV})$. No energy effects related to the reorganization of the solvent molecules in the bulk, other than partial de-solvation of the reactants to form the final complex, can be taken into account with the present model. Negative solvation energies (SE) denote that solvation is a stabilizing factor (see Table 3). Solvation energy increase (SEI) values show that the solvation of the products is poorer than the summation of SE for their corresponding reactants, causing an inherently endergonic SEI. The molecularity of the process, $2 \rightarrow 1$, and the concomitant overall loss of solvation explains SEI values ranging $2-4 \mathrm{eV}$. The computed NEI and SEI values for each compound (Table 3 ) show that the pure (solvation free) CD-borane interaction is always attractive (stabilizing). This fact can be deduced from the balance between NEI and SEI and from the fact that SEs are included in the calculations of total energies. For the complexes, $\left[\mathrm{B}_{10} \mathrm{H}_{10}\right]^{2-@ \beta-C D}$, this interaction over-compensates the positive SEI and makes the complexes more stable than their separate fragments both in solution and in the gas phase. Calculations suggest larger complexation constants $\left(K_{a}\right)$ for $\beta$-CD than other members of the series. It has to be recalled that they feature the lowest SE of the series, probably because of a better match with the CD pocket.

\section{Calculations with no solvation effects}

More can be known about the complexation process by removing the solvation effects. Gas-phase DFT results show that formation of borane@CD complexes from their constituting fragments would be clearly favoured, $\left[\mathrm{B}_{10} \mathrm{H}_{10}\right]^{2-@ \beta-C D}$ being energetically the most advantaged complex (NEI $=-3.59 \mathrm{eV}$ ). As these values are positive in aqueous solution, the loss of solvation stabilization upon complex formation is at the origin. So, in conditions of poorer solvation of the reactants (especially the hydrophilic boranes), formation of borane@CD would be favoured. $\left[\mathrm{B}_{10} \mathrm{H}_{10}\right]^{2-}$ is $0.5 \mathrm{eV}$ more strongly solvated due to its smaller size than $\left[\mathrm{B}_{12} \mathrm{H}_{12}\right]^{2-}$, which could explain the larger affinity of $\left[\mathrm{B}_{12} \mathrm{H}_{12}\right]^{2-}$ towards $\mathrm{CDs}$ in general.

The largest positive SEI values are found with $\beta-C D$, in line with the best structural match between the interacting units and the destabilization due to solvation loss during complexation. The SEl for the formation of $\left[\mathrm{B}_{10} \mathrm{H}_{10}\right]^{2-} @ \beta-C D$ is 1.09 and $1.21 \mathrm{eV}$ larger than that of $\left[\mathrm{B}_{10} \mathrm{H}_{10}\right]^{2-} @ \alpha-C D$ and $\left[\mathrm{B}_{10} \mathrm{H}_{10}\right]^{2-} @ \gamma-\mathrm{CD}$, respectively. These results pinpoint a large release of solvation waters to the bulk during complexation, and could in parallel be associated to a maximal water network recovery. ${ }^{[32]}$ The high $\left[\mathrm{B}_{10} \mathrm{H}_{10}\right]^{2-@ \beta-C D}$ affinity observed experimentally must come from this notable water network recovery related to a chaotropic effect, which entails a large enthalpic stabilization and a $\Delta G<0$ for the reaction. The solvent effects introduced via the COSMO method do not allow us to theoretically quantify the possible chaotropic effect caused by the borane anions in the CD solution since this is described for the present complexation reaction as a disruption (and, later, recovery) of the water network. However, combination of DFT results with experiments can help rationalizing the trends found.

\section{Conclusions}

This work reports the host-guest process involving the anionic cluster $\left[\mathrm{B}_{10} \mathrm{H}_{10}\right]^{2-}$ with $\alpha-, \beta$ - and $\gamma$-cyclodextrins. An X-ray structure was obtained with $\alpha-C D$ and characterized both in the solid state and in solution. Solution studies performed by ESIMS, NMR and ITC with the three CDs allowed demonstrating the formation of 1:1 inclusion complexes between $\left[\mathrm{B}_{10} \mathrm{H}_{10}\right]^{2-}$ and CDs for which the association constants were determined by DOSY NMR, least-squares method applied to Job's plots, and ITC. The determined association constants appear relatively low with an optimal constant obtained with $\beta-C D$ because of a better match of the sizes of the host and the guest. These values are two orders of magnitude lower than that determined for the parent compound $\left[\mathrm{B}_{12} \mathrm{H}_{12}\right]^{2-}$ highlighting the very weak host-guest interaction with $\left[\mathrm{B}_{10} \mathrm{H}_{10}\right]^{2-}$. ITC measurements led to the thermodynamic parameters associated to the encapsulation of $\left[\mathrm{B}_{10} \mathrm{H}_{10}\right]^{2-}$ within the cavities of the cyclodextrin. This process is enthalpically driven and the positive variation of entropy demonstrates that the anionic cluster $\left[\mathrm{B}_{10} \mathrm{H}_{10}\right]^{2-}$ is chaotrope as expected from the work of Assaf, Nau and Gabel. $\left.{ }^{[32}, 33\right]$ Nevertheless due to a bigger charge density in $\left[\mathrm{B}_{10} \mathrm{H}_{10}\right]^{2-}$ 
compared to $\left[\mathrm{B}_{12} \mathrm{H}_{12}\right]^{2-}$, this effect appears much lower in our case. ${ }^{[41]}$ Finally, DFT calculations gave structural mode evidencing a good agreement between the sizes of the boron cluster and the cavity of the $\beta-C D$, while the two others CDs are either too small or over-dimensioned. These calculations gave also fundamental elements allowing better understanding of chaotropic effect in these systems, well-established now for anionic clusters and polyoxometalates. In this field, further work can be envisioned with functionalized $\mathrm{B}_{10}$ clusters and their application in biology.

\section{Experimental Section}

\section{General methods}

Fourier Transform Infrared (FT-IR) spectra were recorded on a 6700 FT-IR Nicolet spectrophotometer, using diamond ATR technique. ATR correction was applied. Elemental analyses. Elemental analyses of $\mathrm{C}, \mathrm{H}$, and $\mathrm{N}$ were carried out by the analytical service of the CNRS at Gif sur Yvette, France. Quantitative analyses of boron were carried out by ICP analysis, performed in CREALINS laboratory in Vernaison, France. Water contents were determined by thermal gravimetric analysis (TGA) with a Mettler Toledo TGA/DSC 1, STAR ${ }^{e}$ System apparatus under oxygen or nitrogen flow $\left(50 \mathrm{~mL} \mathrm{~min}^{-1}\right)$ at a heating rate of $5{ }^{\circ} \mathrm{C} \mathrm{min}{ }^{-1}$.

X-ray diffraction XRD. The diffraction data for $\mathbf{B}_{10}-\mathbf{2} \alpha \mathbf{C D}$ was collected on a Bruker D8 Venture diffractometer with MoKa radiation $(\lambda=0.71073)$ by doing $\varphi$ and $\omega$ scans of narrow $\left(0.5^{\circ}\right)$ frames at $200 \mathrm{~K}$. Absorption correction was done empirically using SADABS. ${ }^{[42]}$ Structures were solved by direct method and refined by full-matrix least-squares treatment against $|F|^{2}$ in anisotropic approximation with SHELX 2017/1[43] in ShelXle program. ${ }^{[44]}$ Hydrogen atoms of $C D$ were refined in geometrically calculated positions. The crystallographic data have been deposed in the Cambridge Crystallographic Data Centre under the deposition codes CCDC 1872088. Crystallographic data and refinement details for $\mathbf{B}_{10-2} \mathbf{2} C D$ are given in Table S1 (SI).

MALDI-TOF mass Spectrometry. MALDI-TOF MS analyses were performed using an UltrafleXtreme mass spectrometer (Bruker Daltonics, Bremen). Acquisitions were performed in reflector or linear positive ion mode. The laser intensity was set just above the ion generation threshold to obtain peaks with the highest possible signal-to-noise $(\mathrm{S} / \mathrm{N})$ ratio without significant peak broadening. The mass spectrometer was externally calibrated using PEG1500 and PEG4500. All data were processed using the program FlexAnalysis (Bruker Daltonics, Bremen) The dihydoxybenzoic acid (DHBA), used as the matrix was purchased from Sigma Aldrich Co. Samples were prepared at a concentration of 60 $\mu \mathrm{M}$ in acetonitrile. The matrix solution was prepared at a concentration of $6 \mathrm{mM}$ in $\mathrm{CH}_{2} \mathrm{Cl}_{2}$. The sample was prepared by mixing the sample solution with matrix solution at a volume ratio of 1:9. After drying, the residues were analyzed by MALDI-TOF technique. Electrospray lonization Mass Spectrometry (ESI-MS) spectra were collected using a Q-TOF instrument supplied by WATERS. Samples were solubilized in water at a concentration of $10^{-4} \mathrm{M}$ and were introduced into the spectrometer via an ACQUITY UPLC WATERS system whilst a Leucine Enkephalin solution was co-injected via a micro pump as internal standard.

Nuclear magnetic resonance (NMR) solution spectra were recorded a $25^{\circ} \mathrm{C}$ in $\mathrm{D}_{2} \mathrm{O} .{ }^{1} \mathrm{H}$ and ${ }^{11} \mathrm{~B}$ NMR were measured with a Bruker Avance 400 $\mathrm{MHz}$ spectrometer equipped with a $5 \mathrm{~mm} \mathrm{BBI}$ probe head and operated at a magnetic field strength of 9.4 T. Quartz NMR tubes are used to avoid background signals from standard glass tubes in case of ${ }^{11} \mathrm{~B}$. Typically, ${ }^{1} \mathrm{H}$ spectra were recorded with one pulse sequence at $30^{\circ}$ flip angle (pulse duration $2.4 \mu \mathrm{s}$ ), using $1 \mathrm{~s}$ recycle delay, $1.6 \mathrm{~s}$ acquisition time and 80 number of scans. 2D ${ }^{1} \mathrm{H}-{ }^{1} \mathrm{H}$ ROESY spectra were carried out on some selected samples using standard phase sensitive pulse sequences in States mode and $300 \mathrm{~ms}$ mixing time. Translational diffusion measurements were performed using Bruker's "ledbpgs2s" stimulated echo DOSY pulse sequence including bipolar and spoil gradients. Apparent diffusion coefficients were obtained using an adapted algorithm based on the inverse Laplace transform stabilized by maximum entropy. ${ }^{[45]}$ In case of samples containing boron, ${ }^{11} \mathrm{~B}$ decoupling was systematically applied during the acquisition of ${ }^{1} \mathrm{H}$ spectra (1D, DOSY and ROESY). The ${ }^{11} \mathrm{~B}$ spectra were recorded with Hahn echo sequence (echo delay $117 \mu \mathrm{s}$ ) under proton decoupling condition, using $0.1 \mathrm{~s}$ recycle delay, $21 \mathrm{~ms}$ acquisition time, and 1024 number of scans. Chemical shifts are reported relative to $1 \% \mathrm{Me}_{4} \mathrm{Si}$ in $\mathrm{CDCl}_{3}$ for ${ }^{1} \mathrm{H}$, and $15 \% \mathrm{BF}_{3} . \mathrm{Et}_{2} \mathrm{O}$ in $\mathrm{CDCl}_{3}$ for ${ }^{11} \mathrm{~B}$ using external standards. ${ }^{[46]}$

Isothermal titration calorimetry ITC. An isothermal calorimeter $\left(\right.$ ITC $_{200}$ MicroCal Inc., USA) was used to determine simultaneously the formation constant and inclusion enthalpy of the complexes formed between $\left(\mathrm{NH}_{4}\right)_{2} \mathrm{~B}_{10} \mathrm{H}_{10}$ and native cyclodextrins $(\alpha-\mathrm{CD}, \beta-\mathrm{CD}$ and $\gamma-\mathrm{CD})$.

Degassed deionised water solutions were used in both cell $\left(V_{0}=202.8\right.$ $\mu \mathrm{L})$ and syringe $(40 \mu \mathrm{L})$. After addition of an initial aliquot of $0.5 \mu \mathrm{L}, 10$ aliquots of $3.6 \mu \mathrm{L}$ of the syringe solution were delivered over $7.2 \mathrm{~s}$ for each injection. This number of ten injections was chosen according to Tellinghuisen's recommendation. ${ }^{[47]}$ The time interval between two consecutive injections was $60 \mathrm{~s}$, which proved to be sufficient for a systematic and complete return to baseline. The agitation speed was set to $1000 \mathrm{rpm}$. The resulting heat flow was recorded as a function of time.

After a preliminary study based on classical titrations, theoretical investigations were carried out in order to optimize the accuracy resulting from distinct experiments, for the different host-guest systems. A combination of dedicated protocols was thus designed, associating release, annihilated release, reverse titration and competitive release. ${ }^{[40]}$ All experimental concentrations are summarized in Table 4.

Table 4: Experimental conditions for ITC measurements.

\begin{tabular}{|c|c|c|c|}
\hline Host & Experiment type & Cell & Syringe \\
\hline \multirow[t]{3}{*}{$\beta-C D$} & Release & Water & $\begin{array}{c}\beta-\mathrm{CD}(5 \mathrm{mM})+ \\
\left(\mathrm{NH}_{4}\right)_{2}\left[\mathrm{~B}_{10} \mathrm{H}_{10}\right](2.5 \mathrm{mM})\end{array}$ \\
\hline & $\begin{array}{l}\text { Annihilated } \\
\text { release }\end{array}$ & $\begin{array}{c}\left(\mathrm{NH}_{4}\right)_{2}\left[\mathrm{~B}_{10} \mathrm{H}_{10}\right] \\
(1.83 \mathrm{mM})\end{array}$ & $\begin{array}{c}\beta-\mathrm{CD}(5 \mathrm{mM})+ \\
\left(\mathrm{NH}_{4}\right)_{2}\left[\mathrm{~B}_{10} \mathrm{H}_{10}\right](2.5 \mathrm{mM})\end{array}$ \\
\hline & Reverse titration & $\beta-C D(5 \mathrm{mM})$ & $\left(\mathrm{NH}_{4}\right)_{2}\left[\mathrm{~B}_{10} \mathrm{H}_{10}\right](1.83 \mathrm{mM})$ \\
\hline \multirow[t]{3}{*}{$\gamma-C D$} & Release & Water & $\begin{array}{c}\gamma-\mathrm{CD}(5 \mathrm{mM})+ \\
\left(\mathrm{NH}_{4}\right)_{2}\left[\mathrm{~B}_{10} \mathrm{H}_{10}\right](2.5 \mathrm{mM})\end{array}$ \\
\hline & $\begin{array}{l}\text { Annihilated } \\
\text { release }\end{array}$ & $\begin{array}{c}\left(\mathrm{NH}_{4}\right)_{2}\left[\mathrm{~B}_{10} \mathrm{H}_{10}\right] \\
(1.83 \mathrm{mM})\end{array}$ & $\begin{array}{c}\gamma-\mathrm{CD}(5 \mathrm{mM})+ \\
\left(\mathrm{NH}_{4}\right)_{2}\left[\mathrm{~B}_{10} \mathrm{H}_{10}\right](2.5 \mathrm{mM})\end{array}$ \\
\hline & Reverse titration & $\gamma-\mathrm{CD}(5 \mathrm{mM})$ & $\left(\mathrm{NH}_{4}\right)_{2}\left[\mathrm{~B}_{10} \mathrm{H}_{10}\right](1.83 \mathrm{mM})$ \\
\hline \multirow[t]{2}{*}{$\alpha-C D$} & Release & Water & $\begin{array}{c}\alpha-C D(5 \mathrm{mM})+ \\
\left(\mathrm{NH}_{4}\right)_{2}\left[\mathrm{~B}_{10} \mathrm{H}_{100}\right](2.5 \mathrm{mM})\end{array}$ \\
\hline & $\begin{array}{l}\text { Competitive } \\
\text { Release }\end{array}$ & $\beta-\mathrm{CD}(5 \mathrm{mM})$ & $\begin{array}{c}\alpha-C D(5 \mathrm{mM})+ \\
\left(\mathrm{NH}_{4}\right)_{2}\left[\mathrm{~B}_{10} \mathrm{H}_{10}\right](2.5 \mathrm{mM})\end{array}$ \\
\hline
\end{tabular}

Density functional theory (DFT). Calculations were performed with the ADF 2016 program, ${ }^{[48]}$ with a TZ2P basis set, medium-core approximation, the OPBE functional[49] with Grimme's dispersion corrections ${ }^{[50]}$ and a high numerical accuracy. The solution effects mimicking water and counterions acting upon the solute molecules have been introduced with the conductor-like screening model (COSMO ${ }^{[51,52]}$ ), which approximates the solution to a polarizable dielectric continuum material, so no explicit water molecules are present in the calculations as defined entities. Thus, formation/disruption of the water network was not examined. A parallel analysis has been carried out for the species in the gas phase, a hypothetical situation that allows us to examine the relevance of solvation on the stabilization energies of the complexes.

\section{Synthesis and isolation of products}

All reagents were purchased from commercial sources and used without further purification. $\left(\mathrm{NH}_{4}\right)_{2}\left[\mathrm{~B}_{10} \mathrm{H}_{10}\right]$ is provided by katchem company.

Crystallization of the inclusion complex $\alpha-C D-\left[B_{10} \mathrm{H}_{10}\right]^{2-:} \alpha-C D(0.63$ $\mathrm{g}, 0.65 \mathrm{mmol})$ was dissolved in water $(25 \mathrm{~mL})$ then $\left(\mathrm{NH}_{4}\right)_{2}\left[\mathrm{~B}_{10} \mathrm{H}_{10}\right](0.1 \mathrm{~g}$ $0.65 \mathrm{mmol}$ ) was added. Crystals were obtained in 5 days, isolated by filtration and dried in air. Yield $0.45 \mathrm{~g}, 32 \%$. FT-IR: $\left(\mathrm{v} / \mathrm{cm}^{-1}\right): 3416(\mathrm{~s}, \mathrm{br}$.$) ,$ $2935(\mathrm{w}), 2523(\mathrm{sh}), 2466(\mathrm{~m}), 1644(\mathrm{~m}), 1424(\mathrm{~m}), 1338(\mathrm{w}), 1151(\mathrm{~s})$, 1081 (s, sh), 1037 (s), 951 (w), $846(w), 756(w), 602(w), 575(w)$ Elemental analysis for $\left(\mathrm{NH}_{4}\right)_{2}\left(\mathrm{~B}_{10} \mathrm{H}_{10}\right)\left(\mathrm{C}_{36} \mathrm{H}_{60} \mathrm{O}_{30}\right)_{2}\left(\mathrm{H}_{2} \mathrm{O}\right)_{21}$ ( $\mathrm{FW}=2478.3$ g. $\mathrm{mol}^{-1}$ ) Calc. (found): H 7.32 (7.27); C 34.89 (34.73); N 1.13 (1.48); B 
4.36 (4.70). TGA shows a weight loss of $15.6 \%$ in the $20-250{ }^{\circ} \mathrm{C}$ temperature range corresponding to the hydration water molecules (calc. $15.2 \%$ ), and a loss of $70.7 \%$ in the $250-800{ }^{\circ} \mathrm{C}$ range corresponding to the loss of $2 \mathrm{CDs}$, the $10 \mathrm{H}$ of $\mathrm{B}_{10}$ cluster and the two $\left(\mathrm{NH}_{4}\right)^{+}$cations (calc. $72.1 \%$ )

\section{Acknowledgements}

We acknowledge the CNRS and the Ministère de l'Education Nationale et de l'Enseignement Superieur (MESRI) for their financial supports. MD thanks AZM association and Institut Universitaire de France (IUF) for financial support of her PhD grant. PAA thanks The French Embassy in Russia for financial support through a Metchnikov grant. XL thanks funding from the Spanish Government (project CTQ2017-87269-P) and the Generalitat de Catalunya (project 2017SGR629).

Keywords: decaborate $\cdot$ cyclodextrin $\cdot$ chaotrope $\cdot$ DOSY NMR - host-guest chemistry

\section{References}

[1] B. R. S. Hansen, M. Paskevicius, H. W. Li, E. Akiba, T. R. Jensen, Coord. Chem. Rev. 2016, 323, 60-70.

[2] N. S. Hosmane, Boron Science: New Technologies and Applications, CRC Press, 2012.

[3] I. B. Sivaev, Chem. Heterocycl. Compds. 2017, 53, 638-658

[4] Y. Zhu, S. Gao, N. S. Hosmane, Inorg. Chim. Acta 2018, 471 , 577-586.

[5] T. J. Udovic, M. Matsuo, W. S. Tang, H. Wu, V. Stavila, A. V. Soloninin, R. V. Skoryunov, O. A. Babanova, A. V. Skripov, J. J. Rush, A. Unemoto, H. Takamura, S. Orimo, Adv. Mater. 2014, 26, 7622-7626.

[6] Y. Zhu, N. S. Hosmane, Eur. J. Inorg. Chem. 2017, 4369-4377.

[7] Y. Zhu, N. S. Hosmane, J. Organomet. Chem. 2013, 747, 25-29.

[8] Y. Zhu, N. S. Hosmane, Coord. Chem. Rev. 2015, 293, 357-367.

[9] B. P. Dash, R. Satapathy, J. A. Maguire, N. S. Hosmane, New J. Chem. 2011, 35, 1955-1972.

[10] D. Naoufal, B. Gruner, P. Selucky, B. Bonnetot, H. Mongeot, $J$. Radioanal. Nucl. Chem. 2005, 266, 145-148.

[11] I. B. Sivaev, V. I. Bregadze, N. T. Kuznetsov, Russ. Chem. Bull. 2002, $51,1362-1374$

[12] Y. Zhu, N. S. Hosmane, Pure Appl. Chem. 2018, 90, 653-663.

[13] E. Hey-Hawkins, C. Viñas-Teixidor, Boron-Based Compounds: Potential and Emerging Applications in Medicine, John Wiley\&sons Ltd, 2018.

[14] Y. Zhu, N. S. Hosmane, Future Medicinal Chemistry 2013, 5, $705-714$

[15] I. B. Sivaev, A. V. Prikaznov, D. Naoufal, Collect. Czech. Chem. Commun. 2010, 75, 1149-1199.

[16] F. Abi-Ghaida, S. Clement, A. Safa, D. Naoufal, A. Mehdi, $J$. Nanomater. 2015, Article Number: 608432

[17] F. Abi-Ghaida, Z. Laila, G. Ibrahim, D. Naoufal, A. Mehdi, Dalton Trans. 2014, 43, 13087-13095.

[18] A. A. Ivanov, C. Falaise, P. A. Abramov, M. A. Shestopalov, K. Kirakci, K. Lang, M. A. Moussawi, M. N. Sokolov, N. G. Naumov, S. Floquet, D. Landy, M. Haouas, K. A. Brylev, Y. V. Mironov, Y. Molard, S. Cordier, E. Cadot, Chem. Eur. J. 2018, 24, 13467-13478

[19] M. A. Moussawi, N. Leclerc-Laronze, S. Floquet, P. A. Abramov, M. N. Sokolov, S. Cordier, A. Ponchel, E. Monflier, H. Bricout, D. Landy, M. Haouas, J. Marrot, E. Cadot, J. Am. Chem. Soc. 2017, 139, 12793-12803.

[20] G. Izzet, M. Menand, B. Matt, S. Renaudineau, L. M. Chamoreau, M. Sollogoub, A. Proust, Angew. Chem.-Int. Edit. 2012, $51,487-490$.
[21] J. Warneke, C. Jenne, J. Bernarding, V. A. Azov, M. Plaumann, Chem. Commun. 2016, 52, 6300-6303.

[22] P. Neirynck, J. Schimer, P. Jonkheijm, L. G. Milroy, P. Cigler, L. Brunsveld, J. Mater. Chem. B 2015, 3, 539-545.

[23] H. Y. V. Ching, D. P. Buck, M. Bhadbhade, J. G. Collins, L. M. Rendina, Chem. Commun. 2012, 48, 880-882.

[24] M. Uchman, P. Jurkiewicz, P. Cigler, B. Gruener, M. Hof, K. Prochazka, P. Matejicek, Langmuir 2010, 26, 6268-6275.

[25] C. Frixa, M. Scobie, S. J. Black, A. S. Thompson, M. D. Threadgill, Chem. Commun. 2002, 2876-2877.

[26] K. Ohta, S. Konno, Y. Endo, Chem. Pharm. Bull. 2009, 57, $307-$ 310

[27] A. Harada, S. Takahashi, J. Chem. Soc.-Chem. Commun. 1988, 1352-1353.

[28] S. M. Eyrilmez, E. Bernhardt, J. Z. Davalos, M. Lepsik, P Hobza, K. I. Assaf, W. M. Nau, J. Holub, J. M. Oliva-Enrich, J. Fanfrlik, D. Hnyk, Phys. Chem. Chem. Phys. 2017, 19, 1174811752.

[29] J. Nekvinda, B. Gruener, D. Gabel, W. M. Nau, K. I. Assaf, Chem.-Eur. J. 2018, 24, 12970-12975.

[30] K. I. Assaf, O. Suckova, N. Al Danaf, V. von Glasenapp, D. Gabel, W. M. Nau, Org. Lett. 2016, 18, 932-935.

[31] K. I. Assaf, D. Gabel, W. Zimmermann, W. M. Nau, Org Biomol. Chem. 2016, 14, 7702-7706.

[32] K. I. Assaf, M. S. Ural, F. F. Pan, T. Georgiev, S. Simova, K. Rissanen, D. Gabel, W. M. Nau, Angew. Chem.-Int. Edit. 2015 $54,6852-6856$

[33] W. M. Nau, K. Assaf, Angew. Chem.-Int. Edit. 2018, 57, 13968 13981.

[34] E. S. Shubina, E. V. Bakhmutova, A. M. Filin, I. B. Sivaev, L. N. Teplitskaya, A. L. Chistyakov, I. V. Stankevich, V. I.

Bakhmutov, V. I. Bregadze, L. M. Epstein, J. Organomet. Chem. 2002, 657, 155-162.

A. J. M. Valente, R. A. Carvalho, O. Söderman, Langmuir 2015, $31,6314-6320$

36] A. J. M. Valente, R. A. Carvalho, D. Murtinho, O. Söderman, Langmuir 2017, 33, 8233-8238.

[37] M. A. Moussawi, M. Haouas, S. Floquet, W. E. Shepard, P. A. Abramov, M. N. Sokolov, V. P. Fedin, S. Cordier, A. Ponchel, E. Monflier, J. Marrot, E. Cadot, J. Am. Chem. Soc. 2017, 139 14376-14379.

[38] H. Y. V. Ching, R. J. Clarke, L. M. Rendina, Inorg. Chem. 2013, 52, 10356-10367.

N. Watfa, D. Melgar, M. Haouas, F. Taulelle, A. Hijazi, D. Naoufal, J. Bonet-Avalos, S. Floquet, C. Bo, E. Cadot, J. Am. Chem. Soc. 2015, 137, 5845-5851.

[40] E. Bertaut, D. Landy, Beilstein J Org Chem 2014, 10, 26302641.

[41] T. Buchecker, P. Schmid, S. Renaudineau, O. Diat, A. Proust, A. Pfitzner, P. Bauduin, Chem. Commun. 2018, 54, 1833-1836.

[42] G. M. Sheldrick, SADABS program for scaling and correction of area detector data, University of Göttingen, Germany., 1997.

[43] G. M. Sheldrick, Acta Crystallogr C Struct Chem 2015, 71, 3-8.

[44] C. B. Hubschle, G. M. Sheldrick, B. Dittrich, J Appl Crystallogr 2011, 44, 1281-1284.

[45] M. A. Delsuc, T. E. Malliavin, Anal. Chem. 1998, 70, 21462148.

[46] R. K. Harris, E. D. Becker, S. M. C. De Menezes, R. Goodfellow, P. Granger, Pure Appl. Chem. 2001, 73, 1795-1818.

[47] J. Tellinghuisen, J. Phys. Chem. B 2005, 109, 20027-20035.

[48] C. F. Guerra, J. G. Snijders, G. te Velde, E. J. Baerends, Theor. Chem. Acc. 1998, 99, 391-403.

[49] N. C. Handy, A. J. Cohen, Mol. Phys. 2001, 99, 403-412.

[50] S. Grimme, J. Antony, S. Ehrlich, H. Krieg, J. Chem. Phys. 2010, 132

[51] A. Klamt, J. Phys. Chem. 1995, 99, 2224-2235.

[52] C. C. Pye, T. Ziegler, Theor. Chem. Acc. 1999, 101, 396-408. 
Entry for the Table of Contents (Please choose one layout)

\section{FULL PAPER}
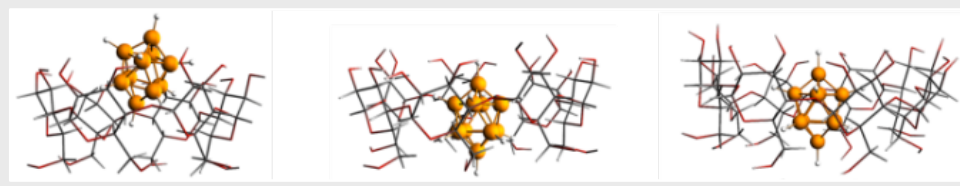

$\left[\mathrm{B}_{10} \mathrm{H}_{10}\right]^{2-:}$ : A new member in the family of chaotropic clusters evidenced through its encapsulation process within cyclodextrins! 